We believe that Bangladesh has lacked coordinated policy decision and enforcement measures to curtail COVID-19 transmission thus far. We urge policy makers to follow WHO guidance and observe other countries' experiences, which point to a strategy of acting decisively, quickly, and early, well before case numbers reach a crisis level for containment. We believe Bangladesh has not yet reached this point, so urgent implementation of a coordinated policy may prevent a spike in cases that is likely to stretch Bangladesh's health system well beyond its capacity.

Acknowledgments. None.

Financial support. No financial support was provided relevant to this article.

Conflicts of interest. All authors report no conflicts of interest relevant to this article.

\section{References}

1. Subramaniam T, Lybrand H. Fact check: US has done more coronavirus tests than South Korea, but not per person. CNN website. https:/edition.cnn.com/ 2020/03/25/politics/coronavirus-testing-trump-south-korea-fact-check/ index.html. Published March 25, 2020. Accessed March 29, 2020.

2. No new COVID-19 cases as testing declines 50\%. Dhaka Tribune website. https://www.dhakatribune.com/bangladesh/dhaka/2020/03/28/no-newcovid-19-cases-as-testing-declines-50. Published March 28, 2020. Accessed March 29, 2020.

3. Number of ICU beds insufficient to combat COVID-19 pandemic. Dhaka Tribune website. https://www.dhakatribune.com/bangladesh/2020/03/21/ number-of-icu-beds-insufficient-to-combat-covid-19-pandemic. Published March 21, 2020. Accessed March 29, 2020.

4. Hindu. COVID-19: Bangladesh Army says troops will be on streets until govt recalls. Hindu website. https://www.thehindu.com/news/international/covid19-bangladesh-army-says-troops-will-be-on-streets-until-govt-recalls/ article31197469.ece. Published 2020. Accessed March 29, 2020.

\title{
COVID-19: Protecting Healthcare Workers is a priority
}

\author{
Francesco Chirico $\mathrm{MD}^{1,2}$ (1) , Gabriella Nucera $\mathrm{MD}^{3,4}$ and Nicola Magnavita $\mathrm{MD}^{1,5}$ \\ ${ }^{1}$ School of Occupational Medicine, Università Cattolica del Sacro Cuore, Rome, Italy, ${ }^{2}$ Health Service Department, State Police, Ministry of Interior, Milan, Italy, \\ ${ }^{3}$ University of Milan, Milan, Italy, ${ }^{4}$ ASST Fatebenefratelli Sacco, FatebeneFratelli Hospital, Milan, Italy and ${ }^{5}$ Department of Woman/Child and Public Health, \\ Fondazione Policlinico "A.Gemelli" IRCCS, Rome, Italy
}

To the Editor-We very much appreciated the letter by Zhou et $\mathrm{al}^{1}$ regarding the protection of Chinese healthcare workers (HCWs) while fighting the COVID-19 pandemic. The authors recognized that the lack of awareness and training, the shortage of personal protective equipment (PPE), and the lack of pointof-care diagnostic tests for were the most important sources of viral spread. In Italy, more infections among HCWs have been recorded than in China. As of April 5, 2020, 12,252 HCWs in Italy had tested positive for SARS-CoV-2, comprising $10 \%$ of Italy's COVID-19 cases $^{2}$; furthermore, 80 medical doctors and 25 nurses had died. Notably, official figures probably underestimate the real impact of COVID-19 on Italian HCWs because many have not been tested and a large majority of coronavirus infections do not result in symptoms or remain paucisymptomatic. ${ }^{3}$ In Italy, HCWs are facing the same issues that Zhou highlighted in Chinese hospitals. SARS-CoV-2 has a high transmissibility rate in indoor environments and, therefore, asymptomatic patients admitted to hospitals without respiratory symptoms have probably spread the virus to unaware and unprotected HCWs. These HCWs have, in turn, infected other patients, visitors, and staff, further amplifying viral transmission. It is well-known that a hospital may amplify an epidemic and that epidemics may overwhelm a hospital's capacity to deliver healthcare services. ${ }^{4}$ Therefore, in addition to general lockdown and social distancing measures, protecting HCWs is a priority in alleviating the burden on the hospitals.
However, in the absence of effective therapies or a vaccination, before the onset of further COVID-19 waves, it is important to relocate the public health emergency response from the hospitals to other locations by integrating the hospital into an overall epidemic response. ${ }^{4}$ In this regard, communication and mass-media information campaigns for the public are crucial.

\section{Acknowledgments.}

Financial support. No financial support was provided relevant to this article.

Conflicts of interest. All authors report no conflicts of interest relevant to this article.

\section{References}

1. Zhou P, Huang Z, Xiao Y, Huang X, Fan XG. Protecting Chinese healthcare workers while combating the 2019 novel coronavirus. Infect Control Hosp Epidemiol 2020 Mar 5 [Epub ahead of print]. doi: 10.1017/ice.2020.60.

2. Istituto Superiore di Sanità. Sorveglianza integrata COVID 19 in Italia. Epicentro website. https://www.epicentro.iss.it/coronavirus/sars-cov-2-sorveglianza-dati. Published April 5, 2020. Accessed April 5, 2020.

3. Day M. COVID-19: four-fifths of cases are asymptomatic, China figures indicate. BMJ 2020;369:m1375. doi: 10.1136/bmj.m1375.

4. World Health Organization. Hospital Preparadness for Epidemics. Geneva: WHO; 2014. \footnotetext{
com

Author for correspondence: Prof Francesco Chirico, E-mail: medlavchirico@gmail.

Cite this article: Chirico F, Nucera G, and Magnavita N. (2020). COVID-19: Protecting Healthcare Workers is a priority. Infection Control \& Hospital Epidemiology, 41: 1117, https://doi.org/10.1017/ice.2020.148
} 